Copyright (C) 2021 University of Bucharest Printed in Romania. All rights reserved

ISSN print: $1224-5984$

ISSN online: $2248-3942$
Rom Biotechnol Lett. 2021; 26(6): 3015-3021 doi: $10.25083 / \mathrm{rbl} / 26.6 / 3015-3021$

Received for publication, March, 18, 2021

Accepted, October, 14, 2021

Original paper

\title{
Aflatoxin in feedstuffs and raw milk in Republic of North Macedonia, occurrence and assessment
}

\author{
DUSHICA SANTA ${ }^{1}$, SONJA SRBINOVSKA ${ }^{1}$, SREKJKO GJORGJIEVSKI ${ }^{1}$, \\ VIKTORIJA GRUEVSKA ${ }^{2}$, FROSINA ARSOVSKA ${ }^{3}$ \\ ${ }^{1}$ Faculty of Agricultural Sciences and Food-Skopje, Institute of Animal Biotechnology Ss. Cyril and \\ Methodius University in Skopje, 16ta Makedonska brigada No 3, 1000 Skopje Republic of North \\ Macedonia, Tel: ++389 23255 100, Fax: ++389 23134310 \\ 2 Avicena DOO Skopje, street 1551 No 5, Industrial zone Vizbegovo, 1000 Skopje, Republic of North \\ Macedonia, Tel: ++389 23079 700, Fax: ++38923079400 \\ 3 “Ekstra Mein" Boris DOOEL- Kumanovo, Republic of North Macedonia
}

\begin{abstract}
The main objective of this research is to estimate the situation of occurance of aflatoxins in feedstuffs and aflatoxin $\mathrm{M}_{1}$ raw cow's milk in Republic of North Macedonia. Detected average concentrations of total aflatoxins in the examined period 2014-2017 were below legal prescribed level. Within the official monitoring programme in the country, 1718 samples of raw cow's milk have been analyzed during 2017 and 2018. Comparison of the data showed that the number of examined samples with values for aflatoxin $\mathrm{M}_{1}$ above the allowed limits, according to the regulation is in 2018 (10 samples) and 2017 (5 samples). Additionally, the calculation of exposure assessment of the human population in North Macedonia demonstrated that the exposure to $\mathrm{AFM}_{1}$ of the adult population in N. Macedonia for 2017 is $0.0563 \mathrm{ng} / \mathrm{kg} \mathrm{bw} / \mathrm{daily}$, and for 2018 is $0.0824 \mathrm{ng} / \mathrm{kg}$ bw/daily. The calculated hazard index (HI) In both years, was lower than one, which means that there are no significant health risks for the consumers. It is important to have continuously low levels of aflatoxins in animal feed and nutrition, especially that the climate changes create more favorable conditions for the development of moulds of Aspergillus.
\end{abstract}

Keywords aflatoxins, $\mathrm{AFM}_{1}$, feed, raw milk, exposure assessment, hazard index

To cite this article: SANTA D, SRBINOVSKA S, GJORGJIEVSKI S, GRUEVSKA V, ARSOVSKA F. Aflatoxin in feedstuffs and raw milk in Republic of North Macedonia, occurrence and assessment. Rom Biotechnol Lett. 2021; 26(6): 3015-3021. DOI: 10.25083/rb1/26.6/3015-3021.

*Corresponding author: DUSHICA SANTA, Faculty of Agricultural Sciences and Food-Skopje, Institute of Animal Biotechnology, Ss. Cyril and Methodius University in Skopje, 16ta Makedonska brigada No 3, 1000 Skopje, Republic of North Macedonia. E-mail: dsanta@,fznh.ukim.edu.mk, Tel: ++389 23255 100, Fax: ++389 23134310 


\section{Introduction}

Maintaining a globally secure way of supplying food and feed is a key issue facing society today. Natural contaminants, such as mycotoxins, pose a real challenge because they are present in many foodstuffs. Mycotoxins are not only harmful to human and animal health, but they also lead to significant economic losses in agriculture, especially in developed countries. These losses are felt by all stakeholders in the chain, from farmers, crop processors, meat and milk producers, distributors, and consumers (Rodrigues et al., 2011). The transfer of aflatoxins from feed to dairy cows depends on a number of nutritional and physiological factors, such as diet, digestibility, animal health, the liver's ability to biotransform, and milk production.

Various studies have shown that the presence of aflatoxin $\mathrm{M}_{1}$ in milk and dairy products is a health problem, because in many countries all age groups regularly, on daily basis, consume these products (Fallah et al., 2009, Udovicki et al., 2019, Schrenk et al, 2020). Milk has the greatest proven potential for occurrence of aflatoxin $\mathrm{M}_{1}$ into the human diet (Duarte et al., 2013). $\mathrm{AFM}_{1}$ is relatively stable during pasteurization, sterilization and storage of milk and dairy products (Iqbal et al., 2015)

From the end of 2012 and the beginning of 2013, public opinion in the Balkans was raised due to the risk of the presence of mycotoxins in food for people in the Balkans and Central European countries, where the European Commission's Rapid Alert System for Food and Feed received 10 alerts of increased AFB1 amounts in maize panel (Dimitrieska-Stojković et al., 2016).

The most well-known is the 2013 aflatoxin M1 epidemic in Serbia. The main source of aflatoxin in milk and dairy products was feed - maize produced in autumn 2012. Hot and dry weather conditions during the second half of the maize production season produced mould and toxin production (Popović et al, 2017).

Due to the present risk occurred in the region, the competent authority in R. North Macedonia in the field of food safety, Food and Veterinary Agency- FVA, issued an order where food business operators in milk processing establishments should carry out procedures to ensure that the legal requirements for maximum levels of mycotoxins are meet by periodically laboratory testing for raw milk at reception, in the premises for milk processing. The maximum levels of aflatoxins and certain other contaminants in food are prescribed in the Rulebook on general food safety requirements (OG 102/2013) in relation to the maximum levels of certain contaminants for raw milk, heat treated milk and milk intended for production of dairy products at maximum level of $0.050 \mu \mathrm{g} / \mathrm{kg}$. The regulation for mycotoxins in the Republic of North Macedonia is harmonized with EU legislation.

However, despite regulatory control measures taken by many countries, correct production and storage measures for feed have to be continuously applied as well as good agricultural practice.

Climate change is anticipated to impact on the presence of aflatoxins in food in Europe and therefore there is a need to continue to monitor aflatoxin occurrence in the light of potential increases (Schrenk et al., 2020)

The aim of this study is to estimate the situation of occurance of aflatoxins in feed and aflatoxin $\mathrm{M}_{1}$ in raw cow`s milk in North Macedonia. According to the results of $\mathrm{AFM}_{1}$ ' presence, the mean daily intake of AFM1 will be estimated for Macedonian consumer for the period of two years through milk consumption, and also, hazard index will be calculated.

\section{Materials and Methods}

Results for detected presence of total aflatoxins in feed were provided by the accredited Animal Feed Analysis Laboratory at the Faculty of Agricultural Sciences and Food in Skopje, using DM-1 method for analysis of total aflatoxins $\left(B_{1}, B_{2}, G_{1}, G_{2}\right)$ in cereals and animal feed by ELISA screening method with limit of detection from 1 to $100 \mathrm{ppb}$, for the period from 01.01.2014 to 31.12.2017.

Within the official monitoring programme for 2017 and 2018 conducted by FVA, 1718 samples of raw cow's milk were taken from the entire territory of the Republic of North Macedonia. The results for this survey have been provided by the FVA. To determine the content of aflatoxin M1 in raw cow's milk, milk control samples were tested by two different techniques, namely: immunoenzymatic tests (ELISA) and chromatographic techniques (IAC and HPLC).

The immunological test used to examine the content of aflatoxin M1 in milk and dairy products, within the monitoring in R. N. Macedonia, was an ELISA test from the German company R-Biopharm AG with a limit of detection (LOD- limit of detection) from 0.005 to $0.05 \mu \mathrm{g} / \mathrm{kg}$. The detection limit for determining the content of aflatoxin M1 in milk in this test is $0.005 \mu \mathrm{g} / \mathrm{kg}$.

All samples have been tasted by ELISA as initial routine screening of the samples. Only suspecious positive results then were analyzed by a chromatographic method. The determination was carried out according to the method ISO 14501: 2007, where the sample is prepared by purification through immunoaffinity column (IAC), and HPLC-FD is used as a detection tool.

The estimation of mycotoxin intake is calculated by the ratio of obtained statistical data and the average daily milk intake per capita in our country. The deterministic method (IPCS, 2009) equation is used to calculate the exposure, as follows:

[toxin] $\mathrm{x}$ [milk consumption]

Estimate of mycotoxin intake $[\mathrm{bw}]$

Where:

[toxin] is the average concentration of mycotoxin in $(\mathrm{ng} / \mathrm{kg})$ [milk consumption] is the amount of milk $(\mathrm{kg})$ consumed per person per day

[bw] is the body weight $(\mathrm{kg})$.

Assessment of mycotoxin intake - in this study refers to aflatoxin M1, expressed in $\mathrm{ng} / \mathrm{kg}$, bw/ day. 
Hazard index (HI) was calculated and based on a proposal by Kuiper-Goodman (1990) who determined the tolerated daily intake for aflatoxin M1 by dividing the TD50 (threshold dose per body weight) with uncertainty factor of 5000. The suggested tolerable daily intake for aflatoxin $\mathrm{M} 1$ is $0,2 \mathrm{ng} / \mathrm{kg}$ body weight / day and is equal to the risk level 1:100 000. It helps in further risk assessment. If $\mathrm{HI}>1$ it poses a risk to the consumer.

\section{Results and discussion}

The occurrence of total aflatoxins in feedstuffs for the four-year period is shown in Table 1 and figure 1.

Table 1. Concentrations (in $p p b$ ) of detected total aflatoxins in feedstuffs for the period 2014-2017

\begin{tabular}{|l|l|l|l|l|l|l|}
\hline Year & No of samples & Mean - ppb & Minimum $\boldsymbol{p p b}$ & Maximum $\boldsymbol{p p b}$ & Standard deviation & CV \\
\hline 2014 & 39 & 4.89 & 0.002 & 16.43 & \pm 4.003 & 81.942 \\
\hline 2015 & 47 & 1.07 & 0.01 & 3.18 & \pm 1.11 & 105.523 \\
\hline 2016 & 18 & 3.57 & 0.01 & 7.61 & \pm 2.60 & 72.721 \\
\hline 2017 & 44 & 0.67 & 0.01 & 7.27 & \pm 1.07 & 159.286 \\
\hline
\end{tabular}

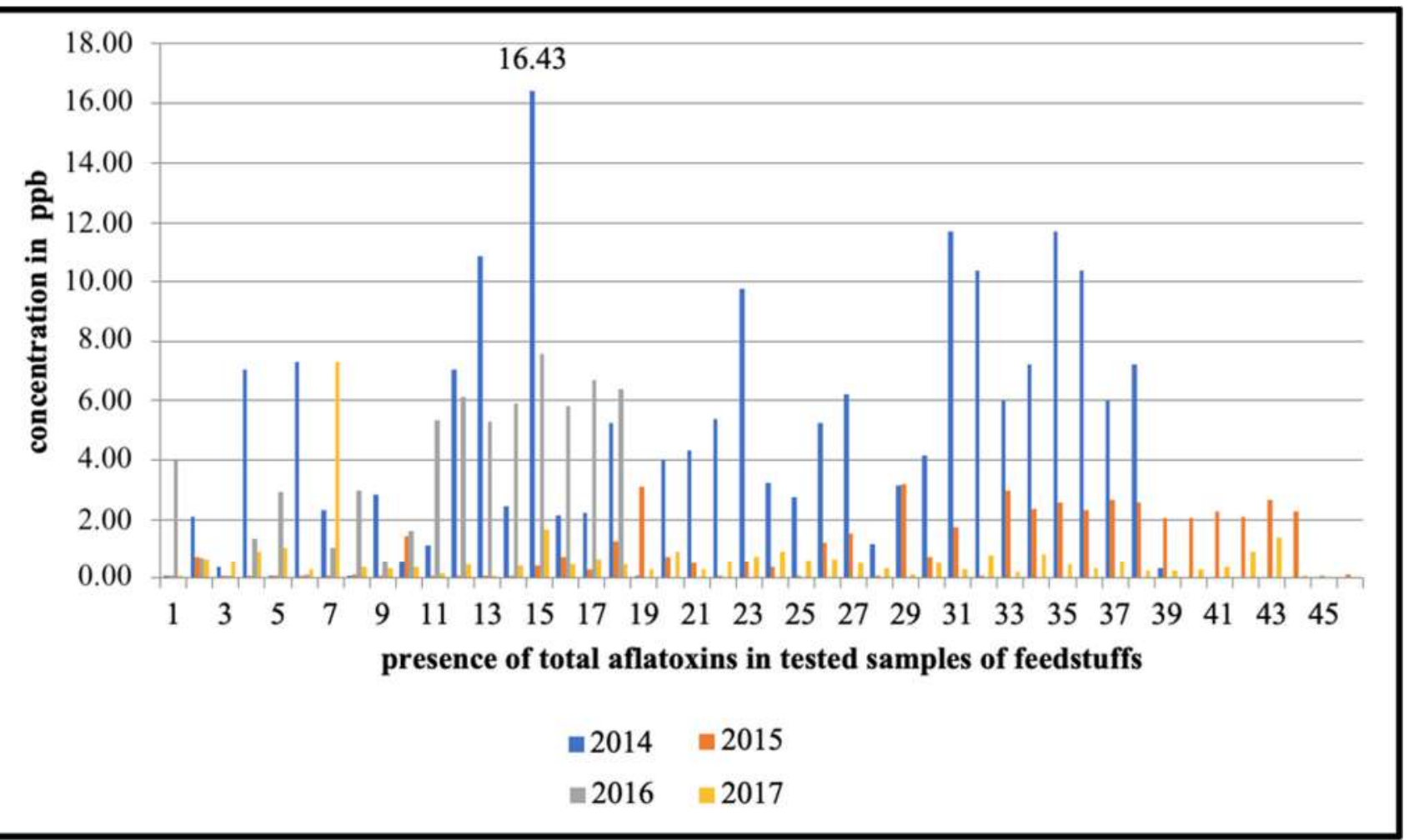

Figure 1. Concentrations (in $p p b$ ) of detected total aflatoxins in feedstuffs for the period 2014-2017

According to the analysis of the detected concentrations of total aflatoxins in feed, presented in Table 1 and Figure 1 , it can be noticed that the highest average concentration was detected in 2014, $4.89 \mathrm{ppb}$, and the lowest in 2017 , $0.67 \mathrm{ppb}$. In 2014, out of a total of 39 tested feed samples the highest detected concentration of total aflatoxins was $16.43 \mathrm{ppb}$.

In another similar study conducted by Kos (2014), in neighboring Serbia, in $60 \%$ of the examined samples of feed corn, the contamination with AF ranged from 1.05 to $70.3 \mu \mathrm{g}$ $/ \mathrm{kg}$. According Spirić et al. (2015), from 281 samples of feed mixtures for dairy cows, $24 \%$ of the examined samples do not meet the appropriate Serbian legal requirements.

According to the Rulebook on general and special requirements for Animal's feed safety (Official Gazette 149/2012) and the Rulebook on the list of undesirable substances in animal feed and the maximum allowed levels (Official Gazette 47/2012), permitted concentrations of total aflatoxins in feed for young categories of animals is $10 p p b$, while for adult categories of animals is $20 p p b$. From the results in our study, we can conclude that the detected average concentrations of total aflatoxins in the 
examined period 2014-2017 do not exceed the prescribed concentrations in the mentioned legal acts.

Although concentrations of total aflatoxins in animal feed are detected at concentrations below the permitted levels, long-term exposure of animals to contaminated food can pose a serious health problem for humans. One of the issues that has to be taken into account is the low economic power of smaller farms to regularly monitor the feed ingredients and to implement good agricultural practice. North Macedonia is country where more than $90 \%$ of cattle farms are with less than 5 dairy cows, where they have less economic and technical ability to control and apply regular monitoring of feed. This is noticed in the neighboring countries also.

Polovinski Horvatović et al. $(2016,2018)$ noted that Serbia and some of the countries in the region have other specific factors like fragmented agricultural production which can additionally increase susceptibility on the occurrence of $\mathrm{AFM}_{1}$ in milk and milk products in the region. Farmers should be properly educated about the reason why these toxins are hazardous to human health and how appropriate intervention should be carried out.

\section{Occurrence of AFM1 in milk}

The highest number of examined samples for 2017 , shown in Table 2 , is noticed in the winter period $(67.5 \%$ of the total number), while the data for 2018 show that the number of tested samples is almost the same in the autumn period (222 samples) and winter period (221 samples). In 2017 more samples of raw cow's milk have been tested (975 samples), compared to 2018 (743 samples). The reason for this decrease of $23.8 \%$ is the decreasing of the number of farms and dairies in our country in 2018, compared to 2017.The highest number of samples, in all seasons, is in the group with values for the content of aflatoxin $\mathrm{M}_{1}$ less than or equal to $0.010 \mu \mathrm{g} / \mathrm{kg}$. The most samples with the content of aflatoxin $\mathrm{M}_{1}$ above the permitted level in 2017 are in the winter period, one sample in the range of 0.051 $0.1 \mu \mathrm{g} / \mathrm{kg}$ and two samples ranged from 0.1 to $0.2 \mu \mathrm{g} / \mathrm{kg}$. The highest number of samples with the content of aflatoxin $\mathrm{M}_{1}$ above the allowed limit in 2018 is in the spring period (6 in total).

Table 2. Concentrations of AFM1 in raw milk, for 2017/2018 according to season

\begin{tabular}{|c|c|c|c|c|c|c|}
\hline \multirow{2}{*}{$\begin{array}{l}\text { Level/ } \\
\text { season }\end{array}$} & \multicolumn{2}{|c|}{ Within the allowed limit } & \multicolumn{3}{|c|}{ Above the allowed limit } & \multirow{2}{*}{$\begin{array}{l}\text { Total } \\
\text { No }\end{array}$} \\
\hline & $\leq 0.010 \mu \mathrm{g} / \mathrm{kg}$ & $\leq 0.050 \mu \mathrm{g} / \mathrm{kg}$ & $\begin{array}{l}0.051-0.1 \\
\mu \mathrm{g} / \mathrm{kg}\end{array}$ & $0.1-0.2 \mu \mathrm{g} / \mathrm{kg}$ & $>0.2 \mu \mathrm{g} / \mathrm{kg}$ & \\
\hline \multicolumn{7}{|l|}{2017} \\
\hline Spring & 240 & 9 & 1 & 1 & 1 & 250 \\
\hline Summer & 198 & 5 & 1 & 1 & 1 & 203 \\
\hline Autumn & 169 & 35 & 1 & 1 & 1 & 205 \\
\hline Winter & 270 & 44 & 1 & 2 & / & 317 \\
\hline \multicolumn{7}{|l|}{2018} \\
\hline Spring & 143 & 21 & 3 & 3 & 1 & 170 \\
\hline Summer & 107 & 21 & 1 & 1 & 1 & 130 \\
\hline Autumn & 194 & 27 & 1 & 1 & 1 & 222 \\
\hline Winter & 176 & 43 & 1 & 1 & 1 & 221 \\
\hline
\end{tabular}

These results are good indicator of the quality of raw cow's milk in our country in terms of contamination with mycotoxins, namely aflatoxin $\mathrm{M}_{1}$, which does lead us to the conclusion that the rules and regulations are generally meet throughout the production process, transport and storage, but also during the preparation and analysis of control samples.
The samples which were confirmed as suspicious positive by ELISA method were analysed by HPLC. Results are presented in Table 3, differentiation of the obtained results is made according to the season and the regulation for mycotoxins in R. N. Macedonia (within / above the allowed limits).

Table 3. Results of raw cow milk samples tested by HPLC in 2017 and 2018

\begin{tabular}{|l|c|c|c|c|}
\hline & \multicolumn{2}{|c|}{$\mathbf{2 0 1 7}$} & \multicolumn{2}{c|}{$\mathbf{2 0 1 8}$} \\
\hline Season & Above the allowed limit & Within the allowed limit & Above the allowed limit & Within the allowed limit \\
\hline Spring & 1 & $/$ & 6 & 2 \\
\hline Summer & $/$ & $/$ & 1 & 3 \\
\hline Autumn & 1 & 2 & 1 & 5 \\
\hline Winter & 3 & 4 & 2 & 4 \\
\hline
\end{tabular}


Out of a total of 11 samples of raw cow milk that were examined by HPLC in 2017, in 55\% of them the presence of aflatoxin M1 is within the allowed limits, and in $45 \%$ are above the allowed limits according to the regulation for mycotoxins in R. N. Macedonia.

The comparison of the data from the two examined years showed that the number of examined samples with values for aflatoxin $\mathrm{M}_{1}$ above the allowed limits, according to the regulation for mycotoxins in $\mathrm{R}$. C. Macedonia, is in 2018 (10 samples) of which $65 \%$ in the spring season (6 samples). However, the highest level for the content of aflatoxin M1 in raw cow's milk was found in the winter period of 2018, $0.215 \mu \mathrm{g} / \mathrm{kg}$, which was four times more of the maximum allowable level of aflatoxin M1 in milk and dairy products.

In studies conducted in neighboring countries there is a much higher percentage of samples that have values above the maximum allowable level of aflatoxin M1 according to the European Union and R. N Macedonia legislation. Milićević et al. (2017) in Serbia reported that $30.1 \%$ of raw cow milk samples are above the maximum allowable level, analyzed in 2016. Škrbić et al. (2014) of 50 samples, in 38 of them $(76 \%)$ found values above the maximum allowed level according to European regulations, with the highest value of $1.44 \mu \mathrm{g} / \mathrm{kg}$ per sample of raw cow milk detected in February (winter period) 2013. In other studies, different results for the content of aflatoxin M1 in raw cow's milk were reported. In 2012, 129 samples of raw cow's milk were tested in Brazil, in which the aflatoxin $\mathrm{M}_{1}$ ranged from 0.0002 to $0.1057 \mu \mathrm{g} / \mathrm{kg}$ (Picinin et al., 2013).

In our study, aflatoxin M1 levels in raw cow's milk are lower than some of the published studies in recent years. However, the comparison between countries is difficult due to differences in the time period of data processing, the season when the samples were analyzed, analytical procedures applied, the manner of storage of control samples, etc. (Škrbić et al., 2014)

In general, aflatoxin $\mathrm{M}_{1}$ levels in milk and dairy products are lower in Europe than in other parts of the world. The highest levels are detected in South Asian countries (Pakistan, Turkey and Iran). The reason for this is differences in climate, geographical region, animal diet, analytical detection methods and differences in farm practice. However, the biggest reason for this difference are the strict regulations in Europe for mycotoxins in animal feed and the food we consume (Milićević et al., 2017).

\section{Estimated daily intake of AFM1 through milk consumption}

With the combination of data on the average daily milk intake and those of the average concentration of aflatoxin M1, an assessment of the exposure of aflatoxin M1 to the human population in the Republic of North Macedonia was performed. The same method of calculation has been used in other studies (Škrbić et al., 2014; Bogalho et al., 2018; Awaisheh et al., 2019; Nejad et al., 2019, Serraino et al., 2019).

The average concentration of aflatoxins in milk is calculated through statistical processing of data obtained from monitoring in the Republic of North Macedonia over a period of two years.
Within the WHO European Programme for Monitoring and Assessment of Dietary Exposure to Potentially Hazardous Substances (GEMS/Food - EURO) a relevant way of assessing low levels of food contamination is presented. In general, there are analytical results that cannot be detected (non-detectable ND) or quantified (nonquantifiable NQ). If qualitative results are in large numbers (more than $70 \%$ of all data) in a study, they can be combined with quantified data to assess exposure to potentially harmful substances, such as mycotoxins.

If we know that environmental pollutants are distributed through a normal logarithm in biological systems and have a standard deviation of 1 when transforming data, then we can estimate the non-quantified results. If there are numerical values for the non-quantified data (in our case $<0.010 \mu \mathrm{g} / \mathrm{kg}$ and $<0.050 \mu \mathrm{g} / \mathrm{kg}$ ), together with the assumption that the logarithmic standard deviation is 1 , then the use of half the quantification limit (LOQ / 2) or the limit of detection (LOD / 2) allows a good estimate of their value. We must be really careful when statistically interpreting the data of certain substances, such as mycotoxins, pesticides and veterinary drugs. These substances may not be present in the control samples intended for testing, but they may still be present in the feed and the food we consume. In this case, it is best to use data that have different detection or quantification limits (WHO GEMS / Food - EURO, 1995).

In this study we have data with two different quantification limits $(<0.010 \mu \mathrm{g} / \mathrm{kg}$ and $<0.050 \mu \mathrm{g} / \mathrm{kg})$ for aflatoxin M1 in raw cow's milk and their number is higher than $70 \%$. According to WHO GEMS / Food EURO (1995) these values are equal to half of the quantification limit (LOQ / 2). According to the above, the results with quantification limit $<0.010 \mu \mathrm{g} / \mathrm{kg}$ in the calculations have a value of $0.005 \mu \mathrm{g} / \mathrm{kg}$, and the results with quantification limit $<0.050 \mu \mathrm{g} / \mathrm{kg}$ have a value of $0.025 \mu \mathrm{g} / \mathrm{kg}$. The same approach has been used in other studies (Milićević et al., 2017; Nejad et al., 2019).

The consumption of milk used to calculate the intake of aflatoxin M1 through the diet was obtained from the State Statistical Office of the Republic of North Macedonia. In order to obtain an accurate value, the summarized data on dairy products (yogurt, sour cream, different types of cheese, whey cheese, butter, etc.) are expressed in milk equivalent. It must be noted that arbitrary value is taken for similar dairy products (example: cheese, kashkaval, hard cheese - trapist and processed cheese), ie they are calculated with the same milk equivalent. To convert the mass of the dairy product into milk equivalent, the following data are used:

○ $8.50 \mathrm{~kg}$ of farm milk needed for production of $1 \mathrm{~kg}$ of cheese;

○ $1,1 \mathrm{~kg}$ of farm milk needed for production of $1 \mathrm{~kg}$ of yogurt or buttermilk;

○ $10.72 \mathrm{~kg}$ of farm milk needed for production of $1 \mathrm{~kg}$ of skim milk powder (CLAL, 2018).

The individual average milk consumption for 2017 is $492.82 \mathrm{~g} / \mathrm{day}$, and for 2018 it is $508.99 \mathrm{~g} /$ day (State Statistical Office of the Republic of Macedonia, 2019). 
When assessing the exposure of the human population in the Republic of North Macedonia to aflatoxin $\mathrm{M}_{1}$ through the consumption of milk and dairy products, the average body weight of an adult was taken as an average value of $60 \mathrm{~kg}$.

The exposure of the adult human population to aflatoxin $\mathrm{M}_{1}$ in our country for 2017 is $0.0563 \mathrm{ng} / \mathrm{kg}$ body weight / day, and for 2018 is $0.0824 \mathrm{ng} / \mathrm{kg}$ body weight. table / day. This is a low value of exposure if we take into account the data obtained from studies in other countries in Europe and the world.

Škrbić (2014) estimated that the highest exposure of the adult Serbian population is in February 2013, with a value of 1,420 ng / $\mathrm{kg}$ body weight / day. Milićević et al., (2017) calculated lower exposure in 2016 than that of Skrbić et al., (2014) with the average daily intake of the male adult population in Serbia of $0.168 \mathrm{ng} / \mathrm{kg}$ body weight / day, and the female $0.144 \mathrm{ng} / \mathrm{kg}$ body weight / day. High values of daily intake of aflatoxin M1 in the adult population have been reported in studies conducted in Spain in $2010(0.305$ $\mathrm{ng} / \mathrm{kg}$ body weight / day) (Cano-Sancho et al., 2010) and Morocco in 2007 (3,26 ng / kg body weight / day) (Zinedine et al., 2007). Lower exposure was reported in 2013 in France and Portugal with values of $0.03 \mathrm{ng} / \mathrm{kg}$ body weight / day and $0.08 \mathrm{ng} / \mathrm{kg}$ body weight / day, respectively (Duarte et al., 2013; Sirot et al., 2013). Internationally, the estimated daily intake of aflatoxin M1 through the consumption of milk and dairy products for the European diet is $0.11 \mathrm{ng} / \mathrm{kg}$ body weight / day (JECFA, 2002) which is higher than the estimated exposure in this study.

The hazard index was calculated through the ratio of the results obtained from the exposure risk assessment and the tolerable daily intake based on proposal of KuiperGoodman (1990). The same method of calculation has been used in other studies (Škrbić et al., 2014; Milićević et al., 2017; Bogalho et al., 2018; Awaisheh et al., 2019; Nejad et al., 2019; Serraino et al., 2019).

The hazard index for 2017 is 0.281 , and for 2018 it is 0.412 . According to the obtained values, it is higher in 2018 compared to 2017. However, this does not pose a major risk to the consumer, as both values are less than $1(\mathrm{HI}<1)$.

\section{Conclusion}

The concentrations of total aflatoxins in feed in the examined period 2014-2017 do not exceed the Macedonian legal requirements. The amount of aflatoxin M1 in milk in our country is in accordance with the recommended daily dose by the Expert Committee on Food Additives (JECFA). With the obtained data, it can be confirmed the importance of having continuously low levels of aflatoxins in animal feed and nutrition, especially that the climate changes create more favorable conditions for the development of moulds of Aspergillus. Due to the stability of aflatoxin M1 during pasteurization, sterilization and storage of milk and dairy products, constant monitoring throughout the production process is necessary in order to reduce the health risks associated with the presence of this toxin. Caution is needed to prevent the occurrence of aflatoxin M1 in milk and dairy products, which can be achieved by: evaluating side effects, selecting an appropriate analytical detection method, assessing exposure, and establishing appropriate ways of prevention and control. The most significant is the reduction of the level of aflatoxin M1 in milk and dairy products, which can be achieved by applying good agricultural practice (GAP) and proper storage of food and feed, in order to control the risk of toxic fungi and contamination of products throughout the food supply chain.

\section{References}

1. Awaisheh SS, Rahahleh RJ, Algroom RM, Al-Bakheit AA et al. Contamination level and exposure assessment to Aflatoxin M1 in Jordanian infant milk formulas. Italian Journal of Food Safety. 2019;8(3). doi:10.4081/ijfs.2019.8263

2. Bogalho F, Duarte S, Cardoso M, Almeida A et al. Exposure assessment of Portuguese infants to Aflatoxin M1 in breast milk and maternal social-demographical and food consumption determinants. Food control. Published online 2018. Accessed March 11, 2021. https://agris.fao.org/agrissearch/search.do?recordID=U S201800111029

3. Cano-Sancho G, Marin S, Ramos AJ, Peris-Vicente J, Sanchis V. Occurrence of aflatoxin M1 and exposure assessment in Catalonia (Spain). Revista Iberoamericana de Micología. 2010;27(3):130-135. doi:10.1016/j.riam.2010.05.003

4. CLAL.Total Dairy Product Exports in Milk Equivalent. 2018. https://www.clal.it/en/index.php?section=dairyPRO D DWT me

5. Dimitrieska-Stojković E, Stojanovska-Dimzoska B, Ilievska $G$, Uzunov $R$ et al. Assessment of aflatoxin contamination in raw milk and feed in Macedonia during 2013. Food Control. 2016;59:201-206. doi:10.1016/j.foodcont.2015.05.019

6. Duarte SC, Almeida AM, Teixeira AS, Pereira AL et al. Aflatoxin M1 in marketed milk in Portugal: Assessment of human and animal exposure. Food Control. 2013;30(2):411-417. doi:10.1016/j.foodcont.2012.08.002

7. Fallah AA, Jafari T, Fallah A, Rahnama M. Determination of aflatoxin M1 levels in Iranian white and cream cheese. Food Chem Toxicol. 2009;47(8):1872-1875. doi:10.1016/j.fct.2009.04.042

8. Iqbal SZ, Jinap S, Pirouz AA, Faizal ARA. Aflatoxin M1 in milk and dairy products, occurrence and recent challenges: A review. Trends in Food Science \& Technology. 2015;1(46):110-119. doi:10.1016/j.tifs.2015.08.005

9. IPCS - International Programme on Chemical Safety. Dietary exposure assessment of chemicals in food. In Principles and methods for the risk assessment of chemicals in food. 2009; Genève, Switzerland: WHO, chapter 6 .

10. JECFA. Evaluation of certain mycotoxins in food. Fifty sixth report of the Joint FAO/WHO expert committee on food additives. Geneva: World Health Organization. 2002 
11. Kos J, Lević J, Đuragić O, Kokić B et al. Occurrence and estimation of aflatoxin M1 exposure in milk in Serbia. Food Control. 2014;Complete(38):41-46. doi:10.1016/j.foodcont.2013.09.060

12. Kuiper-Goodman T. Uncertainties in the risk assessment of three mycotoxins: aflatoxin, ochratoxin and zearalenone. Can J Physiol Pharmacol.1990; 68(7):1017-24. doi: 10.1139/y90-155

13. Milićević DR, Spirić D, Radičević T, Velebit B et al. A review of the current situation of aflatoxin M1 in cow's milk in Serbia: risk assessment and regulatory aspects. Food Addit Contam Part A Chem Anal Control Expo Risk Assess. 2017;34(9):1617-1631. doi:10.1080/19440049.2017.1363414

14. Nejad ASM, Heshmati A, Ghiasvand T. The Occurrence and Risk Assessment of Exposure to Aflatoxin M1 in Ultra-High Temperature and Pasteurized Milk in Hamadan Province of Iran. Osong Public Health Res Perspect. 2019;10(4):228-233. doi:10.24171/j.phrp.2019.10.4.05

15. Picinin LCA, Cerqueira MMOP, Vargas EA, Lana ÂMQ et al. Influence of climate conditions on aflatoxin M1 contamination in raw milk from Minas Gerais State, Brazil. Food Control. 2013;31(2):419-424. doi:10.1016/j.foodcont.2012.10.024

16. Polovinski Horvatović M, Glamočić D, Jajić I, Krstović $\mathrm{S}$ et al. Aflatoxin M1 in raw milk in the region of Vojvodina. Mljekarstvo. 2016;66(3):239-245. doi:10.15567/mljekarstvo.2016.0309

17. Polovinski Horvatović M, Glamočić D, Jajić I, Krstović S. Aflatoxin M1 in Serbia and the Region, Past and Future. Romanian Biotechnological Letters, 23(4): 13736-13743. https://doi.org/10.26327/RBL2018.165

18. Popović R, Radovanov B, Dunn JW. Food scare crisis: the effect on Serbian dairy market. International Food and Agribusiness Management Review. 2017;20(1): 113-127. doi:10.22434/IFAMR2015.0051

19. Rodrigues I, Handl J, Binder EM. Mycotoxin occurrence in commodities, feeds and feed ingredients sourced in the Middle East and Africa. Food Addit Contam Part B Surveill. 2011;4(3):168-179. doi:10.1080/19393210.2011.589034

20. Serraino A, Bonilauri P, Kerekes K, et al. Occurrence of Aflatoxin M1 in Raw Milk Marketed in Italy: Exposure Assessment and Risk Characterization. Front Microbiol. 2019;10. doi:10.3389/fmicb.2019.02516

21. Schrenk D, Bignami M, Bodin L, et al. Risk assessment of aflatoxins in food. EFSA Journal. 2020;18(3):e06040. doi:https://doi.org/10.2903/j.efsa.2020.6040

22. Sirot V, Fremy J-M, Leblanc J-C. Dietary exposure to mycotoxins and health risk assessment in the second French total diet study. Food Chem Toxicol. 2013;52:1-11. doi:10.1016/j.fct.2012.10.036

23. Škrbić B, Živančev J, Antić I, Godula M. Levels of aflatoxin M1 in different types of milk collected in Serbia: Assessment of human and animal exposure. Food Control. 2014;40:113-119. doi:10.1016/j.foodcont.2013.11.039

24. Spirić DM, Stefanović SM, Radičević TM, Đinović Stojanović JM et al. Study of aflatoxins incidence in cow feed and milk in Serbia during 2013. Hemijska industrija. 2015;69(6):651-656. doi:10.2298/HEMIND140619087S

25. Udovicki B, Djekic I, Kalogianni EP, Rajkovic A. Exposure Assessment and Risk Characterization of Aflatoxin M1 Intake through Consumption of Milk and Yoghurt by Student Population in Serbia and Greece. Toxins (Basel). 2019;11(4). doi:10.3390/toxins11040205

26. WHO GEMS/Food-EURO. Second Workshop on Reliable Evaluation of Low-Level Contamination of Food: report on a workshop in the frame of GEMS/Food-Euro, WHO, Kulmbach, 1995; 3-5

27. Zinedine A, González-Osnaya L, Soriano JM, Moltó JC et al. Presence of aflatoxin M1 in pasteurized milk from Morocco. Int J Food Microbiol. 2007;114(1):25-29. doi:10.1016/j.ijfoodmicro.2006.11.001 